\title{
Una lectura decolonial del racismo en Guatemala
}

Luis Fernando Gonzales Lopez

RESUMEN: El presente artículo se refiere a algunas expresiones del racismo que denotan los resabios coloniales en la sociedad guatemalteca, a través del análisis de contenido de imágenes que generaron discusión en torno a la marginalización hacia los pueblos originarios. La decolonialidad es el sustento teórico con el que se abordan los casos seleccionados, luego de una revisión de contenido hemerográfico digital, durante 2017 , para vincular teoría y realidad.

PALABRAS CLAVE: Colonialidad. Marginalización. Raza. Etnia. Decolonialidad.

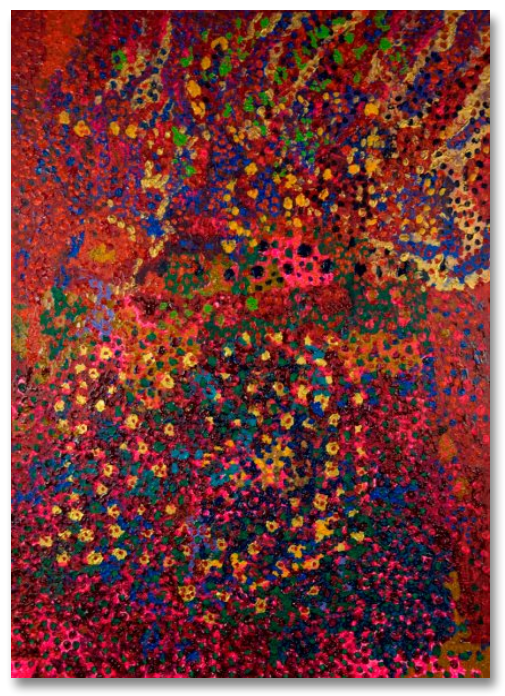

\section{A decolonial reading of racism in Guatemala}

\section{Luis Fernando Gonzales Lopez}

Licenciado en Sociología por la Universidad de San Carlos de Guatemala (USAC). Estudios en Análisis Estratégico y Seguridad, USAC. Maestría en Sociología por la Universidad de Costa Rica (UCR). E-mail: lfgl555@gmail.com
ABSTRACT: This article refers to some expressions of racism, which denote colonial rests in Guatemalan society, through the analysis of image content, which generated discussion about the marginalization towards the original peoples. Decoloniality is the theoretical basis with which the selected cases are addressed, after a review of digital hemerographic content, during 2017, to link theory and reality.

KEYWORDS: Coloniality. Marginalization. Race. Ethnicity. Decoloniality.

RECEBIDO EM: 05/05/2019

Aprovado EM: 26/07/2019 


\section{Introducción}

La historia de América Latina se ha (re)construido siempre desde la perspectiva europea y colonial, dejando por fuera las realidades diversas de los pueblos originarios que habitaban "América" mucho antes de la venida de los colonizadores. En el caso concreto de Guatemala, la diversidad cultural siempre ha estado subordinada por los numerosos mecanismos de exclusión y marginalización, especialmente el racismo como expresión de la colonialidad persistente.

Hablar de América Latina en términos históricos es replicar la versión oficial de quienes han contado la historia del continente, cuyo nombre y existencia inicia a partir del "descubrimiento", aunque eso implique una total invisibilización de las formas de organización social, política y económica que existían antes de la venida de los europeos. "De tal manera, que, en primer lugar, 1492 es el 'comienzo' de América Latina. Es decir, los indígenas con sus espléndidas culturas no tienen significación histórica alguna" (DUSSEL, 1994, p. 63).

En contextos más delimitados como Centroamérica, la cuestión étnico-cultural ha tomado matices distintos, considerando los entornos nacionales que han sufrido un desenvolvimiento histórico diverso, desde los grupos asentados en Panamá hasta la compleja red multicultural que presenta Guatemala. Es a este último país que se le prestará atención en el presente trabajo, tratando de vincular los aportes teóricos de la corriente decolonial con análisis de contenido de material gráfico, para realizar una aproximación analítica a la marginalización de los pueblos originarios.

Es indiscutiblemente amplia la zona de análisis en que se ha tratado de codificar la historia latinoamericana, desde los abordajes culturales, desde los aportes poscoloniales hasta los de la decolonialidad. Y aunque dichas corrientes de pensamiento han estado sujetas a críticas, se inclinará por la segunda para realizar una lectura codificada del racismo como expresión de la colonialidad persistente, específicamente en el contexto guatemalteco. 


\section{Corpus decolonial}

\subsection{Etnia y raza: características estructurales}

partiendo de los aportes de Aníbal Quijano (2013; 2014), quien elabora una conceptualización de la colonialidad del poder, se continuará por una senda que trate de descomponer en sus elementos funcionales y sustantivos la herencia colonial que se continúa replicando en sociedades en donde la dinámica entre diferentes culturas, como ocurre en la sociedad guatemalteca, está fuertemente influenciada por elementos de exclusión entre la cultura dominante y el resto de grupos étnico-culturales que conviven dentro del territorio nacional.

Luego del proceso de descubrimiento, prosiguió la fase de colonización, en donde la dinámica entre los colonizados y colonizadores se sustentó en una categorización basada en la raza, es decir, que implicó la construcción de categorías ligadas a supuestas estructuras biológicas diferenciales entre los grupos, de la misma manera que buscó y consolidó una legitimación de nuevas categorías de seres humanos, entre las que se pueden mencionar, los indios, los negros, los mestizos y los peninsulares.

Aunque fueran las categorías básicas, la dinámica de mestizaje entre cada uno de estos grupos dio origen a una gama mucho más amplia de categorías. "En otros términos, raza e identidad racial fueron establecidas como instrumentos de clasificación social básica de la población". (QUIJANO, 2014, p. 202). Así pues, esta clasificación fue desigual y el constructo que se conocería como raza fue fundamental para la experiencia colonial, porque era el anclaje y motor de la estructuración de los grupos.

A este respecto resulta valioso que:

Cuando se formaliza esa idea en la categoría "raza" y en el "racismo" resultante, no se refiere ante todo a las diferencias fenotípicas entre las gentes, color de piel, ojos, cabello, etc., etc. Porque eso es real, pero banal. No tiene relación con las "facultades" humanas, inteligencia, etc., etc. La idea de "raza" se refiere a que esas diferencias son parte del desigual nivel de desarrollo biológico entre los humanos, en una escala que va desde la 
bestia al europeo. Se trata pues de una diferencia de naturaleza entre los miembros de una misma especie (QUIJANO, 1993 apud RESTREPO; ROJAS, 2010, p.49).

Esta clasificación basada en argumentos que vinculaban la biología con la dinámica social generó la legitimidad necesaria para establecer y vincular a los pueblos originarios a la dinámica del capitalismo europeo, que se sostuvo por la explotación de la mano de obra y la expoliación de los recursos de los nuevos territorios.

Aunque la discusión y las líneas de demarcación a veces parecen difusas, es necesario realizar una breve delimitación en torno a conceptos como raza y etnia, siguiendo lo expuesto por Restrepo y Rojas (2010) quienes señalan que, para Walter Mignolo (2007), la raza se refiere a la cadena de asociación de rasgos fenotípicos, mientras que la etnia está más vinculada a la asociación cultural.

\subsection{Colonialismo y colonialidad}

En virtud de ello, es necesario diferenciar entre colonialismo y colonialidad, entendido el primero de los términos como la dinámica violenta, desigual y de saqueo que fue impuesta en las colonias europeas desde 1492. Por su vez, la colonialidad implica un proceso de largo aliento, que tiene aristas más diversas para detectar su vigencia, aún en la actualidad:

Pero de lo que no han hablado mucho es de la "colonialidad", es decir, del modo en que esas violencias y desigualdades se han vuelto una herencia histórica que permea el modo de ser de los sujetos en estos países hasta hoy, y que funciona con una lógica distinta a la de las instituciones políticas y los modos de dominación colonial o neocolonial (CASTROGOMEZ, 2012b, p. 190).

Esta definición de colonialidad nos permite esbozar al menos tres campos en donde se lleva a cabo y donde se replican sus expresiones. Así, se entiende que existen una colonialidad del poder, una del saber y una del ser. Cada una de estas se desarrolla de manera simultánea y son de carácter complementario. 
Para el enfoque sobre la convivencia de múltiples culturas en un espacio geográfico determinado, es necesario realizar, primero, una delimitación conceptual sobre lo que se entenderá como colonialidad en cada uno de los ámbitos anteriormente citados:

Distinguir tres ejes de la colonialidad que son
irreductibles entre sí, la colonialidad del po-
der, que hace referencia a la dimensión eco-
nómico-política de las herencias coloniales;
la colonialidad del saber, que hace referencia
a la dimensión epistémica de las mismas, y
la colonialidad del ser, que hace referencia a
su dimensión ontológica (CASTRO-GOMEZ,
2012a, p. 219).

Este último acercamiento, al complejo concepto de colonialidad, permitirá orientar de manera más precisa la discusión a la cual se pretende llegar en el presente trabajo. Ya que si bien la historia brinda a la humanidad con datos abundantes para discutir la colonialidad en términos del poder, de los giros epistémicos que se han realizado desde hace algunas décadas en términos de la decolonialidad del saber, se refiere en este trabajo al tercer campo, el de la colonialidad del ser, en términos prácticos y de vivencias emergidas desde los mismos pueblos originarios que cohabitan en el territorio guatemalteco.

En virtud de ello, es posible recurrir a diferentes elementos de la vida social, para evidenciar la forma en que la colonialidad del ser aún persiste en la interacción multicultural que presenta el tejido social guatemalteco. Uno de los elementos que abordará este artículo es la forma cómo la dinámica comunicacional (denotación/connotación) replica los patrones coloniales sobre la lectura del "otro" y que son fácilmente perceptibles en publicaciones de revistas, periódicos y contenido multimedia.

\section{Mapa socio-cultural de Guatemala}

\subsection{De la adscripción cultural de la población}

Es necesario entender que, dentro de la diversidad cultural que existe en Guatemala, se identifican 22 pueblos indígenas que derivan de la civilización maya, a los cuales también deben sumarse la existencia del pueblo Xinca y Garífuna. 
Así pues el mapa étnico, en términos generales, está constituido por cuatro grandes pueblos: Mayas, Xinca, Garífuna y Mestizo. El pueblo maya representa la mayor complejidad ya que está conformado por 22 comunidades lingüísticas y culturales bien definidas:

El pueblo maya está compuesto por 22 comunidades lingüísticas: achi', akateko, awakateko, ch'orti', chuj, ixil, itza', kaqchikel, k'iche', mam, mopan, poqomam, poqomchi', popti', q'anjob'al, q'eqchi', sakapulteko, sipakapense, tektiteko, tz'utujil y uspanteko; y los pueblos garífuna, xinca y ladino" (MSPAS, 2016, p. 09).

A modo de ampliación, es pertinente señalar que los términos ladino y mestizo se usan de manera genérica para referirse a cualquier identidad "no indígena", aunque, en el proceso de reconstrucción histórica, la acepción ladino está más vinculada a mecanismos de exclusión, marginalización y connotaciones peyorativas. Sin embargo, ella es ampliamente usada para referirse a mestizo.

Esta caracterización de la población guatemalteca está mediada por la construcción histórica que se ha realizado de la población indígena, ya que, durante el establecimiento de la colonia, se generó la imagen del "indio", término peyorativo utilizado en Guatemala para referirse a personas indígenas:

[...] los mestizos presentan, desde el momento de su aparición, los rasgos propios de un sector social dislocado; un grupo que tiene frente a sí la tarea de ir encontrando, conforme va creciendo, su ajuste y acomodo en una sociedad cuyas grandes piezas estructurales, preexistentes y perfectamente definidas, van a ofrecerle un campo de desarrollo muy estrecho. Los mestizos no eran ni querían ser indios siervos (MARTíNEZ PELAEZ, 1994, p. 265).

La acotación de Martínez Pelaez se refiere al mestizo como un producto de una mezcla de grupos humanos, en una interpretación netamente biológica; mientras que el concepto de ladino será más amplio, pues incluía grupos humanos diferenciados, pero con connotaciones de exclusión y marginalización social: 
El concepto de ladino es negativo, pues se refiere a todas las personas que en la sociedad colonial no eran indígenas, ni españolas o descendientes puros de españoles. Indica una suma de personas sin especificar sus características (MARTÍNEZ PELAEZ, 1994, p. 271).

El pueblo maya (con sus ramificaciones internas) representa el $40 \%$ de la población total en el territorio guatemalteco. Lamentablemente los datos disponibles en términos censales no han sido actualizados, ya que el último censo poblacional en Guatemala data del 2002. La categorización también presenta serias debilidades, al reconocer únicamente dos categorías (población indígena y no indígena), lo que genera una falsa homogenización en la autodeterminación y adscripción étnico-cultural de las personas (ver tabla 1). Es acá donde toma importancia, al menos para el caso guatemalteco, la colonialidad del ser en un sentido práctico, ya que la definición cultural está determinada por clasificaciones binarias: indígena/no indígena.

Tabla 1 - Autodeterminación y adscripción étnico/cultural de la población en Guatemala

\begin{tabular}{|l|l|l|}
\hline Etnia & Población & Porcentaje \\
\hline Indígena & $5,854,251$ & 40.0 \\
\hline No indígena & $8,782,236$ & 60.0 \\
\hline Total & $14,636,487$ & 100.0 \\
\hline
\end{tabular}

Fuente: Elaboración del autor, con informaciones del Instituto Nacional de Estadística de Guatemala.

\subsection{La cuestión étnico-cultural en la construcción de la sociedad guatemalteca}

Es así como se generan los cimientos para esa clasificación binaria que era propia de los europeos y que, con la colonia, implantaron en los nuevos territorios. "Una nueva tecnología de dominación/explotación, en este caso raza/trabajo, se articuló de manera que apareciera como naturalmente asociada" (QUIJANO, 2014, p. 205). 
La dinámica del capitalismo europeo permitió esta nueva configuración de la historia, haciendo posible entonces que las nuevas identidades geoculturales fueran establecidas a partir de Europa, lo que generó un centralismo determinante (eurocentrismo) en la configuración del mundo moderno:

Ya en su condición de centro del capitalismo
mundial, Europa no solamente tenía el control
del mercado mundial, sino que pudo imponer
su dominio colonial sobre todas las regiones
y poblaciones del planeta, incorporándolas al
"sistema mundo" que así se constituía, y a su
específico patrón de poder. Para tales regio-
nes y poblaciones, eso implicó un proceso de
re-identificación histórica, pues desde Europa
les fueron atribuidas nuevas identidades geo-
culturales. De ese modo, después de América y
Europa, fueron establecidas Africa, Asia y even-
tualmente Oceanía (QUIJANO, 2014, p. 209).

De manera particular en el contexto guatemalteco, la clasificación binaria implantada por los europeos en torno a la clasificación de las personas se perpetuó de manera estructural, lo que generó dinámicas de desigualdad, exclusión y marginalización que perviven en la actualidad:

Todos los países de América Latina sufrieron el proceso de conquista y colonización, que estuvo justificado por una ideología racial, de segregación. Pero en Guatemala, por una razón que no logro entender, en seguida la población se dividió en indígena y ladina; el mestizo nunca entró a formar parte del proyecto nacional ni de la Colonia (CASAUS ARZÚ, 2017, [s.p.]).

Este entramado social, que se sustentó en los aspectos de la colonia, especialmente por la cuestión racial, generó las estructuras de la colonialidad que, posterior a la independencia de la corona española, se tradujeron en el surgimiento de un Estadonación con muchos elementos de racismo estructural. Ese racismo estructural se consolidó tanto a niveles jurídicos, políticos y económicos, como a niveles religiosos, sociales y culturales, a través de los cuales los mecanismos de cada uno de estos campos generaban una marginalización permanente de los pueblos originarios. "Desde la fundación propia del Estado liberal. Por eso es 
que yo sostengo que Guatemala es un Estado racista y una nación eugenésica. Desde el principio se creyó en la necesidad de blanquear la nación para mejorar la raza" (CASAUS ARZÚ, 2017, [s.p.]).

La existencia del aparato burocrático del Estado, forjado en condiciones estructurales que permitían la exclusión de grupos "racialmente" diferenciados (colonialidad del poder), generó toda una consolidación de dinámicas excluyentes, pero económicamente determinadas bajo esa lógica de explotación, en donde se desconocía la participación política de la población indígena. En Guatemala, esa situación se dio hasta prácticamente la segunda mitad del siglo XX y afinca en el imaginario colectivo la idea de subordinación e inferioridad del "indio":

No fue sino hasta en la Constitución Política de la República de Guatemala de 1985 cuando el Estado reconoce por primera vez en toda su historia que el país está conformado por varios grupos étnicos ("pueblos" era un concepto aún lejano en 1985) con derecho a su identidad cultural (ICEFI, 2017, p. 10).

De esta forma, el Estado Guatemalteco, entendido como la unidad político-administrativa central del Estado-nación, genera, reproduce, mantiene y justifica elementos de exclusión y marginalización de un buen sector de la población que, adscrita a otras identidades étnico-culturales, parece quedar fuera o no pertenecer al proyecto "moderno" de nación. Así, pese a la convivencia en un mismo territorio, ni todos gozan a plenitud de la ciudadanía o, al menos, no en el mismo rango que el de las personas "no indígenas". "En la modernidad, ya no será la agresión o la oposición de enemigos, sino la "raza", lo que justifique, ya no la temporal, sino la perpetua servidumbre, esclavitud y violación corporal de los sujetos racializados" (MALDONADO-TORRES, 2007, p. 140).

Es así como la estructura del Estado adopta las bases raciales para su constitución y las replica en otros ámbitos, de manera institucionalizada, permeando la generación y reproducción de arquetipos basados en la exclusión de diferente tipo, cultural, religiosa, social, política y económica. Eso se ve agravado por la desvalorización (marginalización) de personas de pueblos indígenas, que luchan en diferentes esferas de la vida colectiva (política y social) y que, incluso, han sido criminalizadas por su activismo: 
En Guatemala se ha construido un Estado que responde a esos modelos económicos, en el cual los poderes que le han dado forma han visto a los pueblos originarios, más que como pueblos con derechos, como sujetos útiles y objeto de explotación. Así se explican, por un lado, las abismales diferencias en lo económi$\mathrm{co}$, político, jurídico, cultural y social cuando se hace la relación blanco-moreno y, por otro, el desprecio con que se tratan los reclamos de respeto a los derechos específicos de los pueblos indígenas y la permanente y casi salvaje descalificación de figuras políticas indígenas que ejercen su condición de sujetos políticos y encaran la historia (POP, 2017, [s.p.]).

\section{Una mirada crítica desde la decolonialidad}

Habiendo propuesto un marco general en torno a la colonialidad, la composición demográfica (étnica) de Guatemala y los elementos operativos de la colonialidad en el ámbito político, como instancias de reproducción de imaginarios excluyentes, se tratará de esbozar un acercamiento básico al concepto de decolonialidad, pues será de allí donde se hará la lectura analítica de la dinámica socio-étnica en Guatemala.

Partiendo de diferentes autores, es posible hacer una construcción sobre la decolonialidad, entendiéndola como un proceso de deconstrucción que busca no solo realizar una lectura crítica de la historia, sino más bien posicionar a los actores que fueron silenciados, ignorados o invisibilizados en la construcción del mundo moderno, bajo la lógica racial, económica y cultural que se ha referido con anterioridad:

Desde este nuevo posicionamiento epistémico que deconstruye el imaginario sobre lo indio, puede enlazarse el llamado giro decolonial, en el sentido expuesto por CastroGómez y Grosfoguel (2007), como un cambio en las prácticas de conocimiento de los sujetos colonizados, una oposición radical a la colonialidad del poder, del saber y del ser (LEPE LIRA, 2011, p. 51).

Lo que se busca, entonces, es generar nuevas formas de pensar el mundo, la historia, las dinámicas de poder, considerando 
categorías que han estado al margen y tratando de separarse de los lineamientos rígidos que se han inculcado, a partir de la visión de modernidad y progreso. Esos dos conceptos, modernidad y progreso, incluso han sido homogenizados para todo el mundo, partiendo de la experiencia colonial y de los categóricos diferenciados impuestos por los colonizadores.

El giro decolonial es la apertura y la libertad de pensamiento y de formas de vida-otras (economías-otras, teorías políticas-otras); la limpieza de la colonialidad del ser y del saber; el desprendimiento de la retórica de la modernidad y de su imaginario imperial articulado en la retórica de la democracia. El pensamiento decolonial tiene como razón de ser y objetivo la decolonialidad del poder (es decir, de la matriz colonial del poder) (MIGNOLO, 2007, p. 29).

Eso implica necesariamente hacer reflexiones desde las experiencias de quienes sufren exclusión y marginalización, en un sentido étnico-cultural. Es necesario retomar las experiencias colectivas de los pueblos originarios, pero no en un sentido meramente folklórico o como elemento de explotación turística, sino como una forma de reivindicación política e histórica, acompañada de elementos de resignificación que permitirían realizar pasos de la multiculturalidad hacia la interculturalidad. "Por ello, esta perspectiva se inserta dentro de la línea de justificación que concibe a los pueblos indígenas como portadores de un paradigma epistemológico silenciado y negado por la "gramática" cultural dominante [...]" (GARZON LÓPEZ, 2013, p. 307).

\section{De la multiculturalidad a la interculturalidad}

Aunque el giro decolonial y la decolonialidad como constructo epistemológico desafían en términos teóricos la herencia colonial, resulta interesante hacer un acercamiento hacia conceptos un tanto más concretos, en términos de experiencia cotidiana, lo que no implica un completo abandono a la parte macro (estructural) del problema. En consecuencia, se referirá a la convivencia de diferentes grupos étnico culturales dentro del espacio delimitado del territorio guatemalteco y cómo se ha configurado su 
interacción de manera histórica, con mayor énfasis, como es la interacción de dichos grupos en la actualidad.

Muy ligado al grupo modernidad/colonialidad, existen también explicaciones complementarias que tratan de esbozar las formas en que se configuran diversos grupos étnico-culturales que conviven en un espacio delimitado. Es por ello, y considerando la variedad cultural que existe en Guatemala, que se abordarán algunas categorías para entender la forma en que se generan las dinámicas de interacción entre grupos culturales diferenciados y cuál es la situación en la actualidad.

Si la definición de cultura es bastante compleja y no existe un concepto monolítico, la definición de las formas de relacionamiento entre culturas diferentes parece ser aún más compleja; sin embargo, se expondrán acá cinco procesos o dinámicas que se pueden identificar, a lo largo del desarrollo cultural de los grupos humanos. Para tener una definición al menos funcional de cultura, "[...] se puede entender como un conjunto de prácticas y experiencias vinculadas a la nacionalidad, la etnicidad, la religión, los modos de vida, el pensamiento y la praxis particular de un grupo humano" (ZÁRATE PÉREZ, 2014, p. 03).

Es así como el desarrollo cultural atraviesa algunas etapas, desde la fase inicial donde se consolida, generando los mecanismos internos de arraigo entre sus miembros (intraculturalidad) hasta donde en una dinámica de intercambio e interacción entre grupos culturales diferenciados se genera una hegemonía por parte de una cultura en específico, lo que genera la fase de transculturalidad. Sin embargo, es interesante describir las etapas intermedias que señala Zárate Pérez (2014) en forma de un proceso gradual en el desarrollo cultural:

- Intraculturalidad: se considera la primera etapa en donde el desarrollo es hacia adentro y de manera autónoma de un grupo en específico;

- Multiculturalidad: en esta fase, se supone la existencia de grupos culturales diferentes con condiciones diferenciadas, pero sin nexos entre ellos. Según los aportes de Walsh (2008), esta etapa se da en condiciones de desigualdad estructural, aunque las relaciones no sean interactivas. Se señala que esta categoría es occidental y, por ello, eurocéntrica; 
- Pluriculturalidad: implica la yuxtaposición e intercambio cultural entre grupos, pero aún se mantienen identidades autónomas. En esta etapa, a diferencia de la anterior, se refiere a una convivencia simultánea;

- Interculturalidad: este es un concepto polisémico, ya que se ha burocratizado en los discursos políticos. Sin embargo, para efectos de la sociología, se entenderá como la relación entre dos o más culturas que mantienen relaciones en igualdad de condiciones, respetando de manera mutua formas de vida y pensamiento;

- Transculturalidad: fase final del desarrollo cultural en donde un grupo ejerce influencia y dominio sobre el resto. Las relaciones son eminentemente de dominación y con tendencias homogenizantes.

Estas categorías ayudarán a establecer una aproximación de mejor forma al contexto guatemalteco, ya que en términos jurídicos la Constitución Política de la República de Guatemala, en su artículo 58, habla de la identidad en términos de identidad cultural, según la cual "se reconoce el derecho de las personas y de las comunidades a su identidad cultural de acuerdo a sus valores, su lengua y sus costumbres" (GUATEMALA, 1993, p. 12). Sin embargo, no hace una visibilización de los pueblos que históricamente han conformado la sociedad guatemalteca.

\section{La cuestión racial en la historia reciente de Guatemala}

Aunque reconstruir la historia cultural de Guatemala resultaría demasiado extenso, es necesario hacer una breve mención a la etapa del conflicto armado interno (1960 - 1996), que estuvo influenciado por el elemento étnico-cultural, situación que trató de conciliarse dentro de la agenda de los Acuerdos de Paz Firme y Duradera, que fueron firmados en diciembre de 1996. No obstante, al carecer de carácter vinculante, la temática étnico-cultural no ha sido abordada con seriedad y de manera significativa en los últimos 20 años. 
Es conocido el caso de la represión de Estado que se vivió en Guatemala durante el tiempo del conflicto armado interno (1960 1996), pero resulta aún más delicado el tema de los abusos cometidos contra la población civil no combatiente, mayoritariamente indígena y asentada en el altiplano (región occidente). Dicha situación ha sido abordada ampliamente tanto por la academia guatemalteca como extranjera y es parte de la Reconstrucción de la Memoria Histórica, para avanzar en los procesos de justicia transicional que, aún hoy, se siguen dilucidando en los tribunales de justicia. Entre los múltiples textos académicos o literarios que pueden encontrarse, es posible encontrar referencia a: Carlos Guzmán Böckler con "Donde enmudecen las conciencias" (1986), Víctor Montejo con "Testimonio: muerte de una comunidad" (1987), Victoria Sanford con "Violencia y genocidio en Guatemala" (2003), Marta Elena Casaus Arzú con "Genocidio: ¿La máxima expresión del racismo en Guatemala?" (2008) y Marcio Palacios Aragón con "Violencia y genocidio en Guatemala: el caso ixil" (2017), por mencionar algunos.

Tan racista es el Estado guatemalteco que utilizó a sus aparatos represivos para cometer genocidio. ¿Por qué cree que en otros países de América Latina donde hubo enfrentamientos armados, no hubo genocidio? Eso no es casual. Si se comparan los Estados racistas donde se ha producido genocidio, es porque ha habido racismo de Estado. El racismo en Guatemala está incrustado en el Estado, forma parte de su genealogía. Eso hace que sea tan difícil desmontarlo; porque está en las propias instituciones (CASAUS ARZÚ, 2017, [s.p.]).

Los apuntes de Casaús Arzú dan una idea de cómo ha funcionado los mecanismos de racismo, aún provenientes de la misma estructura del Estado y que han configurado, por ende, las condiciones de vida de la población indígena. Y en este punto, se retoman los postulados de la colonialidad del ser, ya que fueron tan interiorizados los elementos de la colonialidad que prácticamente todas las instituciones de la sociedad guatemalteca reproducen patrones de exclusión, en relación con la categoría de raza, que de manera más precisa y correcta sería étnico-cultural, pero que desafortunadamente se usan como sinónimo: 
Tardé diez años en entender que es el propio Estado y sus instituciones, sus aparatos ideológicos los que producen y reproducen el racismo: la familia, la escuela, la religión, los medios de comunicación; y también sus aparatos represivos (CASAUS ARZÚ, 2017, [s.p.]).

De acuerdo con esto, se puede señalar que existe una amplia atmósfera de colonialidad en la sociedad guatemalteca, tanto en los ámbitos políticos, epistémicos y ontológicos. Aunque los primeros dos ámbitos no fueron abordados tan ampliamente en el presente trabajo, se pude afirmar que, en el tercer ámbito, la estructuración excluyente basada en los principios de raza siguen funcionando de manera activa, a tal punto que se han interiorizado prácticas, conductas y estereotipos que no han permitido construir una nación en donde se reconozca, respete e incluya a la diversidad de pueblos que cohabitan en Guatemala.

Vinculando los aportes de la decolonialidad con el análisis de contenido de publicaciones de medios de información digitales y algunas revistas que promueven la industria de alta costura, se presenta la posibilidad de evidenciar como los estereotipos y la construcción del "otro" siguen presentes en el imaginario colectivo de una gran parte de la población guatemalteca. A continuación, se presentan dos publicaciones difundidas en diferentes medios digitales de información que muestran que la marginalización de la población indígena, principalmente de la mujer indígena, se ha naturalizado, en términos políticos, culturales y económicos. 


\section{El contenido gráfico como expresión de colonialidad}

\subsection{Los casos de las revistas Look ${ }^{1}$ y María Chula ${ }^{2}$}

El acercamiento teórico conceptual, desde el enfoque decolonial, permitirá entender, en términos de experiencias concretas, como se percibe, construye, reproduce e interioriza la cuestión étnico-cultural en Guatemala. Para ello, se referirá a dos casos que tuvieron una cobertura significativa en medios masivos de información nacionales, porque colocaron en la palestra pública un tema difícil de abordar.

En julio de 2017, la revista guatemalteca de moda Look publicó una fotografía (ver imagen 1) que fue tildada de racista, clasista y excluyente, puesto que mostraba a una mujer rubia con un vestido de alta costura, rodeada de mujeres indígenas ataviadas con sus trajes regionales, generando un contraste chocante, al menos para el contexto guatemalteco. Las críticas en las redes sociales de la revista fueron tales que la marca se vio obligada a publicar un comunicado, aclarando la situación e informando que dicha fotografía sería retirada de la publicación:

Los lectores argumentaron que tal portada contradecía lo que trataba de explicar el equipo editorial como parte de la propuesta de la imagen, la cual "celebraba los logros de TODAS las mujeres tanto en portadas, artículos...", y cuya intención era promover el respeto y lo positivo de Guatemala (PEREZYERA, 2017, [s.p.]).

Si bien la revista colgó el comunicado en todas las redes sociales digitales que utiliza, los comentarios se polarizaron, pues algunas personas consideraban que era una exageración quejarse de racismo cuando se exhibía la diversidad cultural presente en Guatemala. Por otra parte, algunos argumentaban que mostrar a las mujeres indígenas era una folklorización o cosificación de las mismas, por mostrarlas en posición de sumisión u "ornamento" y no como parte integral de la fotografía.

\footnotetext{
1 Revista digital guatemalteca enfocada a promover contenido de interés para la mujer. En su sitio electrónico, se define como "la revista que captura la esencia de la mujer actual y la cultura de la moda y estilo de vida de Latinoamérica".

2 Empresa enfocada a la comercialización de prendas de vestir para mujeres, con diseños de tejidos de pueblos indígenas.
} 


\section{Imagen 1 - Portada de la revista Look de julio de 2017}

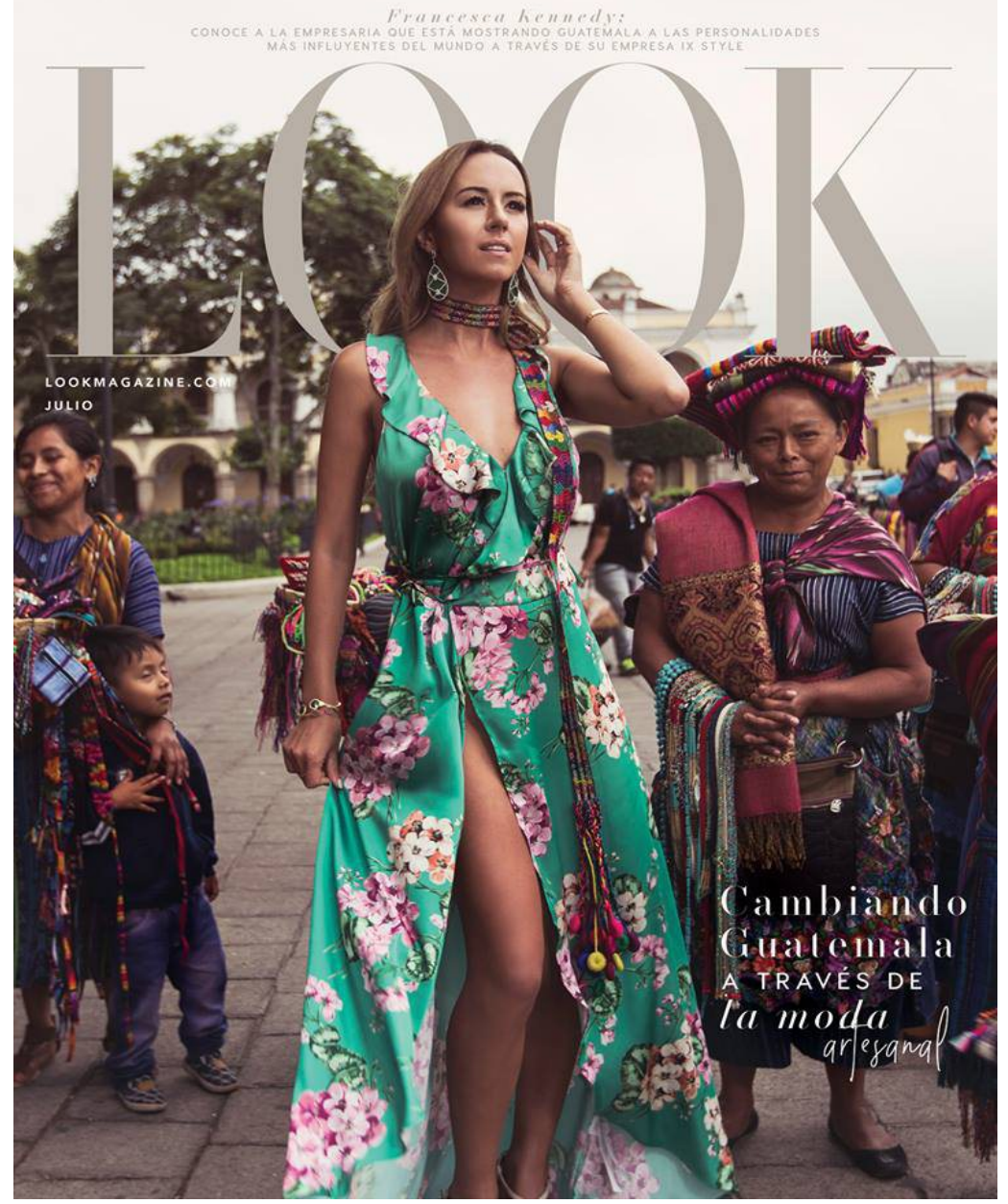

Fuente: Página de Look Magazine en la red social Facebook, en 04 de julio de 2017.

Si bien las imágenes tienen contenidos polisémicos, la palabra da sentido a la existencia de lo que se enuncia, eso sí, siempre partiendo de quien tiene la posibilidad de enunciar. Así, la estructuración social se vuelve más compleja cuando se toman para el análisis otras variables como el sexo, género o clase social, que están en plena interacción con la cuestión étnico-cultural. 
El análisis de contenido de la imagen (portada) conlleva dos niveles. El primero es el de la denotación que es la simple descripción de los elementos que componen el producto gráfico, es decir, la presencia de 6 personas de diferentes grupos étnicos, edades y con atuendos diversos. De esas seis personas, una mujer rubia y con una prenda de vestir elegante se localiza en el foco central de la imagen, mientras que en el plano secundario dos mujeres con atuendos indígenas, una de ellas acompañada por un niño, complementan la imagen. Atrás de la fotografía, dos hombres observan caminando, cuyo enfoque es difuminado. La fotografía fue tomada en la Plaza Central de la Antigua Guatemala, un lugar sumamente turístico. El segundo nivel es el de la connotación del producto gráfico, que puede complejizarse si se toman en cuenta los argumentos esbozados con anterioridad, en donde se manifiesta la subalternidad en la que se ha colocado a los pueblos y a las mujeres indígenas en la construcción histórica de las sociedades latinoamericanas, pero particularmente para el presente caso, de la sociedad guatemalteca.

Así pues, se resalta y se expresa una posición de superioridad a la modelo rubia que acapara la parte central de la imagen, cuyo lenguaje corporal denota un lenguaje comercial y atípico para una escena tan cotidiana. Ya las mujeres indígenas, acompañadas del niño, se muestran en su rutina diaria, en la venta de bisutería y otros productos artesanales, como parte más bien ornamental (de contraste) a la modelo.

Considerando las múltiples lecturas que el producto fotográfico permite, se logró consignar en una entrevista la voz de una de las mujeres indígenas que apareció en la fotografía que generó polémica, pero, más que posicionarla como sujeto político y resignificar su testimonio como una "experiencia otra", se le victimizó y posicionó en un lugar infravalorado, destacando únicamente lo que el relato hegemónico permite visibilizar:

Los comunicadores del sitio GuatemalanArts.com.gt buscaron a una de las mujeres que apareció en dicha publicación. Se trata de Aura Chiriz Ajpuac, una mujer trabajadora que enseña a sus hijas, 
el oficio que aprendió de su madre, hacer collares, bufandas y artesanías de su pueblo, San Andrés Itzapa, Chimaltenango. Los cuales vende en las empedradas calles de La Antigua Guatemala. "Mi esposo se enteró y me dijo que no me anduviera metiendo en cosas en las que no me llaman", comentó a sus interlocutores (GORDILLO, 2017, [s.p.]).

Los matices con que se abordó esa entrevista periodística muestran la posición del "colonizador" que dibuja, plasma, relata y describe la posición del "colonizado", el inferior que está enmarcado dentro de sus límites impuestos por términos raciales, pero, en este caso, también por etiquetas que determinan su posición en la sociedad guatemalteca por su sexo, género y clase social.

En tal sentido, y bajo la lógica de Poder-Saber-Ser, propuesto por el enfoque decolonial, los esquemas y patrones de dominación han permeado a la base sustancial del ser humano, la subjetividad y, de allí, generan dinámicas que se consolidan en actos de poder, en una mutua influencia entre los tres ámbitos enlistados:

La colonialidad, materializada en un patrón de dominación como colonialidad del poder, ejerce su peso sobre la subjetividad y el conocimiento, por ejemplo en la literatura donde puede descubrirse la permanencia de los relatos coloniales sobre los indios (LEPE LIRA, 2011, p. 50).

Es así como el segundo caso, el de la tienda María Chula, ocurrido también en 2017, en donde la cuestión étnico-cultural volvió a ser un caso de polémica en medios masivos de información y redes sociales digitales (ver imagen 2): 


\section{Imagen 2 - Publicidad de la tienda María Chula}

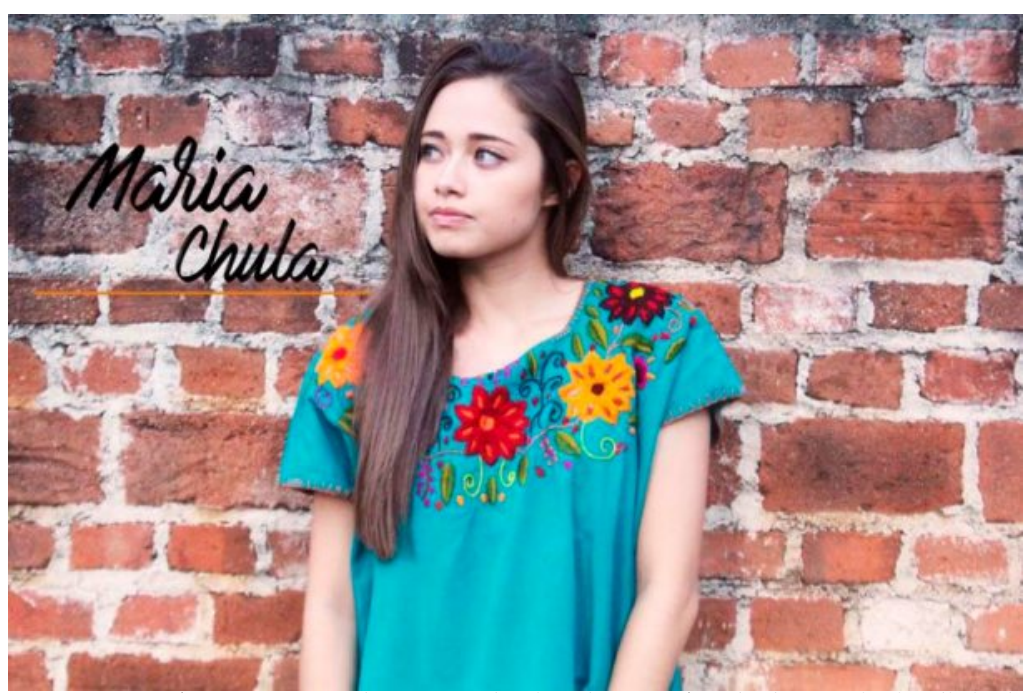

Fuente: ¿Qué va a pasar ahora con la tienda "María Chula"?, Diario digital Soy 502, en 18 de julio de 2017.

Para entender este caso, es necesario contextualizar la vida cotidiana de Guatemala. María es un nombre común entre la población indígena y mestiza, pero en un sentido histórico se ha generado una connotación peyorativa, en donde a cualquier mujer con rasgos morenos o indígenas se les dice "maría"3 y, para el caso de los hombres, el nombre utilizado de manera genérica es "pedro". Con esto, se trata de despersonalizar al individuo simplemente creyendo que "todos los indios son iguales", los cuales son el producto de la exclusión y marginalización a la que han estado sometidos los pueblos indígenas.

La empresaria guatemalteca María Andrea Flores creó una tienda virtual a la que nombró María Chula y en la que promocionaba ropa de alta costura con elementos textiles de pueblos indígenas. Derivado del breve contexto expuesto anteriormente y por cuestiones de asociaciones (prejuicios y prenociones), Flores

3 El uso de la minúscula en "maría" trata de expresar el sentido de subordinación que conlleva su enunciación. Lo mismo se pasa con el nombre de "pedro". 
fue demandada ante la Comisión Presidencial Contra el Racismo (CODISRA) por atentar contra la dignidad de las mujeres indígenas.

La polémica surgió, al igual que en el caso de la revista Look, mayoritariamente en redes sociales digitales, en donde parte de los internautas señalaban como "exageración" dicha denuncia, mientras otros señalaban la vinculación entre el término "chula" (lo mismo que guapa, bonita, agradable) con la construcción de "indígena" por el nombre que es comúnmente utilizado para minimizar a la mujer indígena. Según ellos, ello reproducía una idea racista de que todas las mujeres que visten con indumentaria regional se llaman María:

Miriam Domínguez, titular de Codisra, cuenta que en el caso de "María Chula" recibieron la denuncia hace un mes y medio por parte de una organización de mujeres que defienden la indumentaria maya. Sin embargo, aclaró que la denuncia "no es por el nombre". "No era el nombre en sí, pues hay una coincidencia con que la dueña de la tienda se llama María. Es María acompañado del calificativo "Chula" y que la joven vende blusas típicas. Es algo histórico: a todas las mujeres indígenas las discriminan llamándolas a todas 'María' y las tratan mal", aseguró la Comisionada (¿QUÉ..., 2017, [s.p.]).

En el plano de la denotación, la imagen muestra una composición mucho más simple, ya que se trata de una modelo, con una prenda de vestir, con detalles de colores bordados. La mujer se recuesta levemente sobre una pared de ladrillo con la mirada sutilmente dirigida hacia la izquierda. La connotación quizá es un tanto más sutil, pero la representación de lo que se podría definir como apropiación cultural es la base del análisis. Además del uso de palabras que históricamente han formado parte de un lenguaje que marginaliza y excluye, por lo expuesto anteriormente en torno al uso del nombre María, no existe un reconocimiento a poblaciones indígenas por usar diseños tradicionales de su indumentaria. Los tejidos, diseños y bordados característicos de los trajes de los pueblos indígenas han sido menospreciados históricamente, lo que también ha llevado a procesos de resignificación política por parte la población indígena a lo largo del tiempo. Sin embargo, 
en esta composición gráfica, se muestra a una persona que no es común que utilice este tipo de prendas de vestir, sumado a que los diseños han sido apropiados por una empresa sin el reconocimiento a la población que históricamente lo ha utilizado.

\section{Conclusiones}

Es posible expresar que la colonialidad sigue presente en los ámbitos de la configuración de las sociedades centroamericanas, particularmente en la sociedad guatemalteca, que, en la actualidad, es la nación que más diversidad étnico-cultural presenta en la región. El caso de Guatemala es interesante debido a la cantidad de pueblos originarios que cohabitan en un mismo territorio y que, además, representan un alto porcentaje de la población. Según la caracterización estadística elaborada en 2012 por el Instituto Nacional de Estadística de Guatemala (INE), la población que se identifica como indígena es del 40\%, pero aun así ella no posee un reconocimiento ni respeto pleno por parte de un Estado que funcionaliza y reproduce el racismo, como muestra de esa colonialidad originaria.

Las propuestas del giro decolonial y de la decolonialidad, en general, han ayudado y permitido la generación de nuevos relatos que se contraponen, a manera de resistencia política, epistémica u ontológica, a la hegemonía eurocéntrica de la cual está plagada toda la existencia de "América desde su descubrimiento". La tarea no es fácil, inmediata ni espontánea, ya que crear nuevas formas de interacción, nuevas categorías y nuevas subjetividades no son procesos que se logren de manera inmediata, porque como lo han señalado quienes construyen pensamiento decolonial, para denunciar los excesos del colonizador, se sigue utilizando su mismo idioma, sus mismas categorías y sus mismos paradigmas. "En consecuencia, es tiempo de aprender a liberarnos del espejo eurocéntrico donde nuestra imagen es siempre, necesariamente distorsionada" (QUIJANO, 2013, p. 242).

El tema de la diversidad cultural, entendida quizá en términos de multiculturalidad, ya que el andamiaje institucional no 
ha permitido siquiera transitar hacia la pluriculturalidad, es el reto histórico en Guatemala. Las condiciones de vida de la población en general están determinadas por un sistema excluyente y clasista, situación que se agrava si se pondera la variable étnica para realizar los análisis de pobreza y pobreza extrema, ya que los grupos más afectados son los indígenas. Sin duda alguna, la variable género nos aporta una veta más de análisis para comprender la rígida estructura de la sociedad guatemalteca, que se sigue fundamentando en elementos "raciales" y patriarcales para su funcionamiento.

Los casos sometidos al análisis de contenido permiten la aproximación hacia elementos cotidianos que expresan la interiorización y naturalización de procesos de la colonialidad del ser, que se han permeado y perpetuado en el imaginario colectivo de una parte de la población guatemalteca. Desde el uso del lenguaje o de la lectura de población marginalizada en contextos cotidianos como la plaza, el mercado o la calle, muestra como el rasgo fenotípico sigue siendo un elemento determinante para la interacción entre grupos cultural y étnicamente diferenciados.

Si bien el análisis se realizó solamente con dos publicaciones difundidas durante 2017, es indudable que el mismo patrón puede rastrearse en otros medios de comunicación masiva y en otros formatos, tanto por el uso de elementos gráficos como lingüísticos que reafirmen la jerarquía racial que aún subsiste en el tejido social guatemalteco como resabios de esa colonialidad histórica. Sin duda, la discusión y el abordaje desde diferentes disciplinas del problema étnico-cultural en Guatemala permitirán ir ampliando la veta de análisis, para trascender de una mera multiculturalidad hacia una interculturalidad plena y efectiva en términos de reconocimiento de la diversidad sociodemográfica que encierra el territorio nacional. Estas pequeñas líneas se suman a la intención de ver desde ópticas diversas el tema étnico-cultural en Guatemala, apostado al análisis de contenido de material difundido en redes sociales digitales. 


\section{REFERENCIAS}

¿QUÉ va a pasar ahora con la tienda "María Chula"? Soy502, Ciudad de Guatemala, 18 jul. 2017. Comunidad. Disponible en: <https://www. soy502.com/articulo/va-pasar-tienda-maria-chula-68696>. Acceso en: 08 nov. 2018.

CASAUS ARZÚ, M. E. Marta Elena Casaús Arzú o el indio como la maldición de la oligarquía. Plaza Pública, Ciudad de Guatemala, 20 feb. 2017. Disponible en: <https://www.plazapublica.com.gt/content/marta-elenacasaus-arzu-o-el-indio-como-la-maldicion-de-la-oligarquia>. Acceso en: 08 nov. 2018.

CASTRO-GOMEZ, S. Los avatares de la crítica decolonial: entrevista dada a Grupo de Estudios Sobre Colonialidad (GESCO). Tabula rasa, Bogotá, $\mathrm{n}$. 16, p. 213 -230, 2012a. Disponible en: < https://www.redalyc.org/articulo. oa?id=39624572012>. Acceso en: 07 nov. 2018.

Genealogía de las herencias coloniales: entrevista dada a Fernando Hernández González y Tania Rodríguez Mora. Andamios, Ciudad de México, v. 9, n. 20, p. 187 - 199, 2012b. Disponible en: <http://www.scielo. org.mx/scielo.php?script=sci_arttext\&pid=S1870-00632012000300009\&ln $\mathrm{g}=\mathrm{es} \& \mathrm{nrm}=\mathrm{iso}>$. Acceso en: 09 nov. 2018.

DUSSEL, E. 1492: el encubrimiento del otro: hacia el origen del mito de la modernidad. La Paz: UMSA; Plural Editores, 1994.

GARZON LÓPEZ, P. Pueblos indígenas y decolonialidad: sobre la colonización epistemológica occidental. Andamios, Ciudad de México, v. 10, n. 22, p. $305-331,2013$. Disponible en: <http://www.scielo.org.mx/ scielo.php?script=sci_arttext\&pid=S1870-00632013000200016\&lng=es\&nr m=iso>. Acceso en: 05 nov. 2018.

GORDILLO, I. Aura Chiriz habla de la portada que causó polémica porque ella apareció en "segundo plano". Publinews Guatemala, Ciudad de Guatemala, 13 jul. 2017. Disponible en: <https://www.publinews.gt/gt/ tendencias/2017/07/13/aura-chiriz-habla-la-portada-causo-polemicaaparecio-segundo-plano.html>. Acceso en: 03 nov. 2018.

GUATEMALA. Congreso de la República (1985). Constitución Política de la República de Guatemala. Diario Oficial, 1985, tomo 226, diario 41.

ICEFI - Instituto Centroamericano de Estudios Fiscales. Inversión Pública en Pueblos Indígenas: según el presupuesto ejecutado en 2015. Informe de organización. Guatemala, [s.n.], 2017.

LEPE LIRA, L. M. Colonialidad y decolonialidad en la literatura indígena mexicana: el pensamiento fronterizo en Natalio Hernández. Anuario Americanista Europeo, Helsinki, n. 9, p. 49 - 63. Disponible en: <https:// 
halshs.archives-ouvertes.fr/halshs-00826799/document>. Acceso en: 08 nov. 2018.

MALDONADO-TORRES, N. Sobre la colinialidad del ser: contribuciones al desarrollo de un concepto. In: CASTRO-GOMEZ, S.; GROSFOUEL, R. (coords.). El giro decolonial: reflexiones para una diversidad epistémica más allá del capitalismo global. Bogotá: Siglo del Hombre Editores, 2007. p. $127-167$.

MARTINEZ PELAEZ, S. La patria del criollo: ensayo de interpretación de la realidad colonial guatemalteca. Ciudad de México: Ediciones en Marcha, 1994.

MIGNOLO, W. El pensamiento decolonial: desprendimiento y apertura. In: CASTRO-GOMEZ, S.; GROSFOUEL, R. (coords.). El giro decolonial: reflexiones para una diversidad epistémica más allá del capitalismo global. Bogotá: Siglo del Hombre Editores, 2007. p. 25 - 46.

MSPAS - Ministerio de Salud Pública y Asistencia Social. Perfil de salud de los pueblos indígenas de Guatemala. Ciudad de Guatemala: Organización Panamericana de la Salud; Organización Mundial de la Salud, 2016.

PEREZYERA, A. Tras polémica racista, revista guatemalteca elimina su portada de julio. SPNOTICIAS, Ciudad de Guatemala, 7 jul. 2017. Estilo de vida. Disponible en: <https://www.sdpnoticias.com/estilo-devida/2017/07/07/tras-polemica-racista-revista-guatemalteca-eliminasu-portada-de-julio>. Acceso en: 08 nov. 2018.

POP AC, A. Racismo en Guatemala: más que una falla social, una ideología de dominación. Plaza Pública, Ciudad de Guatemala, 12 sep. 2017. Disponible en: <https://www.plazapublica.com.gt/content/racismo-enguatemala-mas-que-una-falla-social-una-ideologia-de-dominacion $>$. Acceso en: 10 nov. 2018.

QUIJANO, A. Raza, etnia y nación: cuestiones abiertas. In: VV.AA. José Carlos Mariátegui y Europa: el outro descubrimiento. Lima: Amauta, 1993. p. $167-189$.

Colonialidad del poder, eurocentrismo y América Latina. In:

Cuestiones y horizontes: de la dependencia histórico-estructural a la colonialidad/descolonialidad del poder. Buenos Aires: CLACSO, 2014. p. $777-832$.

RESTREPO, E.; ROJAS, A. Inflexión decolonial: fuentes, conceptos y cuestionamientos. Popayán: Universidad del Cauca, 2010.

WALSH, C. Interculturalidad crítica, pedagogía decolonial. In: VILLA, W.; GRUESO, A. (comp.). Diversidad, interculturalidad y construcción de ciudad. Bogotá: Universidad Pedagógica Nacional, 2008. p. 35 - 57. 
ZÁRATE PÉREZ, A. Interculturalidad y decolonialidad. Tabula rasa, Bogotá, n. 20, p. 91 - 107, 2014. Disponible en: <http://www.revistatabularasa. org/numero-20/05-Zarate.pdf>. Acceso en: 03 nov. 2018. 